\title{
Bacteriemia por Campylobacter fetus subsp fetus en un paciente inmunosuprimido
}

\author{
Alberto Fica C, Víctor Illanes R., Andrea Sakurada Z., Mario Vidal C. y M. Eugenia Valenzuela M.
}

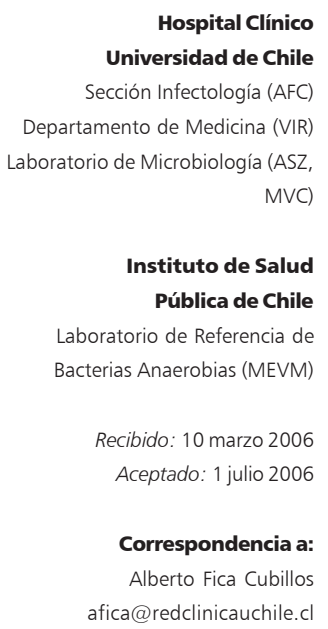

Hospital Clínico

Sección Infectología (AFC) Departamento de Medicina (VIR) $\mathrm{MVC})$ afica@redclinicauchile.cl

\section{Bacteraemia due to Campylobacter fetus in an immune suppressed patient}

We report a case of bacteraemia by Campylobacter fetus subsp. fetus in a 77 year-old woman with immunosuppression secondary to steroid use. Diagnosis was suspected by finding Gram negative curved rods in blood cultures taken after 4 days of a febrile illness without local findings. Diarrhea was not present. There was no consumption of undercooked meat or non-pasteurized milk and no contact with pets. The patient was treated with sulbactam-cefoperazone due to the coexistence of urinary tract infection by multiresistant E. coli. The outcome was favorable and albeit susceptibility was not assessed, quinolone resistance was presumed because illness appeared during ciprofloxacin prophylaxis for urinary tract infection. In contrast to $C$. jejuni infections, $C$. fetus infections are associated to debilitated or immunosuppressed patients, bacteraemia is predominant, diarrhea is rarely observed and disease is not self-limited.

Key words: Campylobacter fetus, bacteraemia, immunesupression.

Palabras claves: Campylobacter fetus, bacteriemia, inmunosupresión.

\section{Introducción}

$\mathrm{E}$ 1 género Campylobacter es conocido por su asociación con brotes de gastroenteritis aguda en países desarrollados, en relación a agua y alimentos contaminados. Tanto las especies Campylobacter jejuni como Campylobacter coli se han reportado predominantemente en estos cuadros, así como relacionadas al síndrome de Guillain Barré ${ }^{1,2}$.

En contraste, la especie Campylobacter fetus se ha asociado preferentemente a infección extraintestinal y afecta especialmente a pacientes con enfermedades debilitantes. También es una causa de abortos espontáneos en animales ${ }^{1,2}$. Recientemente observamos un caso de infección del torrente sanguíneo por $C$. fetus en una paciente inmunodeprimida, que nos pareció de interés publicar.

\section{Caso clínico}

Mujer de 77 años, ingresó a fines de julio del año 2005 por un cuadro de 4 días de fiebre hasta $39^{\circ} \mathrm{C}$ con calofríos pero sin síntomas focales. Como antecedente destacaba la preexistencia de un síndrome nefrótico diagnosticado un año antes por una glomerulopatía membranosa tipo II, tratado con prednisona en dosis inicial de $50 \mathrm{mg}$ diarios y $10 \mathrm{mg}$ desde entonces. Además había sido tratada nueve meses antes por un cuadro de pielonefritis aguda y luego otro evento similar en junio del 2005 que no requirió internación. Desde esa fecha la paciente recibía en forma ininterrumpida profilaxis antimicrobiana con ciprofloxacina (a dosis no precisada). Tres meses antes de ser ingresada presentó un cuadro autolimitado de diarrea acuosa, que no requirió consulta médica o medicamentos. No había antecedentes de tenencia de mascotas.

En el examen de ingreso la paciente se veía enflaquecida (48 $\mathrm{kg}$ IMC de $20,2 \mathrm{~kg} / \mathrm{m}^{2}$ ), deshidratada, normotensa, con taquicardia, febril y sin compromiso de conciencia o signos focales. Los resultados de laboratorio demostraron anemia importante (hematocrito $27,6 \%$, hemoglobina $9,2 \mathrm{gr} / \mathrm{dL}$ ) y ausencia de leucocitosis o leucopenia. La radiografía de tórax fue normal y el sedimento de orina demostró leucocituria (10-12 por campo microscópico), sin piocitos, microhematuria ni cilindros. Los valores de proteinuria eran bajos ( $75 \mathrm{mg} / \mathrm{dL}$ y en forma estimada $<1,5 \mathrm{~g} /$ día) y se detectó una insuficiencia renal descompensada por la deshidratación (clearence de creatinina de $20 \mathrm{~mL} / \mathrm{min}$ ) que se corrigió con la rehidratación a $45 \mathrm{~mL} / \mathrm{min}$. A pesar de una hipoalbuminemia leve $(3,3 \mathrm{gr} / \mathrm{dL})$ no había evidencia de actividad del síndrome nefrótico. No se contó con un recuento de linfocitos en condiciones 
estables antes del ingreso ni recuento de inmunoglobulinas. La anamnesis dirigida no pesquisó el consumo de alimentos sospechosos.

Se inició tratamiento empírico con ceftriaxona intravenosa con una mejoría progresiva de la paciente. Los hemocultivos tomados al ingreso revelaron la presencia de bacilos gramnegativos curvos (crecimiento a las 13 horas de incubación). El estudio se complementó con una tinción de violeta-bicarbonato (tinción de Hucker). Simultáneamente se recibió el resultado del urocultivo que demostró Escherichia coli $>10^{5} \mathrm{ufc} / \mathrm{mL}$, multiresistente a ampicilina, amikacina, cefalosporinas, quinolonas y cotrimoxazol. La cepa era productora de $\beta$-lactamasas de espectro extendido. Los resultados de estas pruebas microbiológicas motivaron un ajuste del tratamiento antimicrobiano a los tres días del ingreso, reemplazándose ceftriaxona por sulbactam/ cefoperazona. Algunos días después se recibió la confirmación del Instituto de Salud Pública (ISP), laboratorio de referencia, sobre el aislamiento de Campylobacter fetus subs. fetus en sangre. En el ISP se efectuó una tinción específica para visualización de flagelos que confirmó su presencia ${ }^{3}$. La cepa presentó pruebas oxidasa, catalasa y, nitratasa positivas, creció en caldo glicina al $1 \%$ (que permitió ser diferenciado de C. fetus subsp. venerealis), se desarrolló a $25{ }^{\circ} \mathrm{C}$ y presentó una prueba negativa para hidrólisis de hipurato e indoxyl acetato. En contraste a lo descrito para $C$. jejuni, fue susceptible a cefalotina y resistente a ácido nalidíxico.

Dada la favorable respuesta observada con sulbactam/cefoperazona, se prolongó este tratamiento durante 14 días, siendo reemplazado al alta por amoxicilina/ác clavulánico oral por 3 semanas adicionales. No se tomaron hemocultivos de control ni se contó con estudio de susceptibilidad in vitro de Campylobacter en nuestro caso. Durante la hospitalización se descartó la endocarditis infecciosa con una ecocardiografía trans-torácica. La evolución de la paciente, luego de terminar el tratamiento, fue favorable hasta un mes de seguimiento; sin embargo, debió reingresar dos meses más tarde por un cuadro de decaimiento y dolor en el hemiabdomen inferior asociado a una pancolitis documentada mediante una TAC abdominal. El cuadro no tuvo un diagnóstico etiológico específico, no se asoció a hemocultivos positivos a Campylobacter sp, ni hubo una tinción positiva en deposiciones para este agente; tampoco estuvo asociada a la detección positiva de citotoxina de Clostridium difficile. Respondió favorablemente a sulbactam/cefoperazona y metronidazol utilizados en forma empírica para cubrir la sospecha de una colitis infecciosa incluyendo inicialmente una colitis pseudomembranosa por $C$. difficile. La ecocardiografía de control no mostró complicaciones y una colonoscopia realizada 3 meses más tarde resultó normal. En su último control en marzo del 2006, la paciente se encontró en buenas condiciones, con su insuficiencia renal estable.

\section{Discusión}

Aspectos generales y microbiología. El género Campylobacter se caracteriza por su morfología curvo-espirilar, la que permite la sospecha temprana en fluidos estériles o en cuadros de diarrea inflamatoria. Estas bacterias son móviles, gracias a la existencia de flagelos unipolares o bipolares, y la mayor parte son microaerófilas estrictas y capnofílicas. Tienen un metabolismo no fermentativo ni oxidativo, su obtención de energía proviene de moléculas de aminoácidos o de intermediarios de 4 ó 6 carbonos del ciclo de Krebs ${ }^{1}$.

Integrado este género por numerosas especies, $C$. jejuni constituye la especie predominante en medicina humana $^{1,2}$. Sin embargo, otras especies han sido identificadas ocasionalmente en pacientes, siendo C. fetus una especie que posee características epidemiológicas, microbiológicas y clínicas distintivas de C. jejuni, lo que permite su sospecha e identificación. Campylobacter fetus se divide a su vez en dos subespecies denominadas subsp. fetus y subsp. venerealis ${ }^{1}$.

En oposición a $C$. jejuni, que se asocia a patología en pacientes en general sanos y que puede presentarse en brotes de enfermedades transmitidas por agua y/ o alimentos, $C$. fetus afecta principalmente a pacientes debilitados o inmunocomprometidos, actuando como agente oportunista; rara vez se manifiesta en brotes. Sólo infrecuentemente $C$. fetus se asocia a diarrea; predomina como una causa de infección sistémica especialmente con bacteriemia, estableciendo con ello un claro contraste con C. jejuni, el que rara vez ocasiona infecciones extraintestinales ${ }^{1,2}$. Por otra parte, en las infecciones por $C$. jejuni la evolución clínica es, en general, favorable y en su mayoría autolimitadas, lo que difiere de las infecciones por C. fetus, las que siempre requieren tratamiento antimicrobiano y, debido a la condición basal de los hospederos, puede ocasionar la muerte.

En nuestra paciente la identificación de la subespecie fetus se efectuó mediante el aislamiento de la bacteria en frascos de hemocultivos automatizados con la visualización de bacilos gramnegativos curvos espirilares en las tinciones de Gram y Hucker. La identificación definitiva se efectuó en el laboratorio de referencia del ISP, mediante pruebas bioquímicas y discos diferenciales. Se debe destacar que $C$. fetus tiene la capacidad de crecer en rango de temperatura entre $25^{\circ} \mathrm{C}$ y $37^{\circ} \mathrm{C}$, 
siendo variable su crecimiento a $42{ }^{\circ} \mathrm{C}$. En cambio, $C$. jejuni se desarrolla en el rango de $32{ }^{\circ} \mathrm{C}$ a $42{ }^{\circ} \mathrm{C}$.

Que la sospecha diagnóstica se planteara por la visualización de bacilos gramnegativos curvos al Gram no es accidental, debido a que este es un hallazgo trascendental en el diagnóstico de este patógeno. Además, el uso de una tinción especial (Hucker) para mejorar la resolución diagnóstica fue de gran apoyo. Ésta ha sido utilizada también como método de tamizaje en pacientes con diarrea para el reconocimiento de Campylobacter sp. en nuestro país, con una alta especificidad aunque con una sensibilidad limitada ${ }^{4}$.

Manifestaciones clínicas. En contraste a C. jejuni, que se asocia a cuadros de diarrea, $C$. fetus es infrecuente en patología humana y se ha asociado principalmente a bacteriemias o infecciones extraintestina$\operatorname{les}^{1,5}$. Las bacteriemias constituyen la principal fuente de muestras clínicas de C. fetus (69\%), seguidas por deposiciones $(20 \%)$ y una variedad que incluye aorta, bilis, líquido sinovial, LCR, ascitis y pleura. ${ }^{6}$ Los sitios de recuperación de $C$. fetus reflejan la diversidad de cuadros clínicos posibles además de las bacteriemias y diarreas, incluyendo casos de meningitis, peritonitis, aneurisma "micótico" y artritis séptica entre otros. Las bacteriemias por $C$. fetus se concentran en pacientes con diabetes mellitus, cirrosis, o inmunocompromisos de diferentes causas tales como terapia corticoesteroidal, trasplante de órganos, infección por VIH o presencia de tumores sólidos o neoplasias hematológicas $^{5,7-9}$. El riesgo de infecciones asociadas a corticosteroides depende de la condición de base, de la dosis diaria utilizada y/o de la dosis acumulada, apareciendo un mayor riesgo con dosis $>10 \mathrm{mg}$ al día de prednisona o una dosis acumulada $>700 \mathrm{mg}$, tal como ocurrió en nuestra paciente ${ }^{10}$.

También se ha reportado ocasionalmente bacteriemias por C. fetus en hospederos inmunocompetentes ${ }^{11}$. Entre los factores de virulencia de C. fetus destaca la capacidad de resistir el efecto bactericida del suero, lo que explica su asociación con bacteriemias 9 .

Fuentes de contagio. Las diferentes especies de Campylobacter tienen un amplio reservorio animal que incluye vacunos, ovinos, porcinos, aves y reptiles. La transmisión de este patógeno se asocia al consumo de carne inadecuadamente cocida, leche no pasteurizada, agua contaminada o al contacto con mascotas. La forma de adquisición de este microorganismo no fue dilucidada en este caso. Las infecciones C. fetus también han estado posiblemente ligadas al consumo de sopa de tortuga ${ }^{9}$, dietas naturistas que contienen extractos líquidos de vísceras crudas de animales $^{12} \mathrm{o}$ a prácticas homosexuales ${ }^{13}$.
Estudios previos desarrollados en Chile se han centrado en las especies $C$. jejuni y $C$. coli permitiendo establecer que el primero de ellos ocupa el tercer lugar como agente de diarrea de causa bacteriana en lactantes. Para esta misma población, su incidencia resultó ser 7 veces más frecuente que los casos asociados a Salmonella o E. coli enteroinvasora ${ }^{14}$.

Tratamiento y pronóstico. Con un tratamiento antimicrobiano apropiado, el pronóstico de las bacteriemias por C. fetus es en general favorable $e^{5,7,9,11}$. Sin embargo, es adverso en los raros casos de infección recurrente, los que no sobrepasan a 3\% del total de las infecciones por esta especie $\mathrm{e}^{6,8}$.

C. fetus es susceptible in vitro a numerosos antimicrobianos, incluyendo ampicilina, gentamicina, cefalosporinas de tercera generación y carbapenémicos. Los aislados de esta subespecie presentan susceptibilidad intermedia o resistencia en frecuencia variable a eritromicina, tetraciclina y quinolonas ${ }^{6}$. La resistencia a estas últimas se ha incrementado notoriamente debido al uso de medicamentos en la crianza de ganado ${ }^{2}$. En nuestra paciente la resistencia a quinolonas se puede presumir debido a que desarrolló su enfermedad durante un esquema profiláctico para infección urinaria con ciprofloxacina. Ella fue tratada con sulbactam/cefoperazona para cubrir al mismo tiempo una infección urinaria por E. coli multiresistente. Este antimicrobiano ha sido utilizado con éxito para tratar C. fetus previamente ${ }^{7}$. Los antimicrobianos utilizados en estos pacientes incluyen quinolonas, $\beta$-lactámicos y compuestos carbapenémicos ${ }^{15}$. No se ha reportado presencia de $\beta$-lactamasas en este subespecie ${ }^{6}$. Dado que al momento del alta de la paciente esta información se desconocía, se mantuvo un tratamiento complementario con amoxicilina/ác clavulánico por vía oral.

La duración del tratamiento y la vía de administración han sido variables en la literatura publicada, aunque es común observar tratamientos parenterales iniciales con traspaso a terapia oral luego de la estabilización, y una duración aproximada de 3 a 4 semanas para evitar el riesgo de infección recurrente.

Prevención. La ingestión de carne de ave adecuadamente cocida, el consumo de leche pasteurizada, las prácticas higiénicas durante la preparación de alimentos para evitar una contaminación cruzada y la educación de pacientes inmunocomprometidos son estrategias preventivas eficaces para disminuir la incidencia de las infecciones por agentes de este género ${ }^{2}$.

De acuerdo a nuestra información, este caso corresponde a la primera comunicación de una infección por C. fetus en nuestro país. Sus características son concordantes a lo descrito en otras latitudes, inclu- 
yendo el inmunocompromiso presente en la paciente, la bacteriemia como infección extraintestinal, la ausencia de diarrea y su evolución favorable.

\section{Resumen}

Comunicamos un caso de bacteriemia por Campylobacter fetus subsp. fetus en una paciente inmunosuprimida de 77 años, usuaria de corticoesteroides. La sospecha fue planteada por el hallazgo de bacilos gramnegativos curvos en los hemocultivos tomados al cuarto día de evolución de un cuadro febril sin diarrea. La paciente fue tratada con sulbactam/ cefoperazona debido a la coexistencia de una infección urinaria por Escherichia coli multiresistente. No hubo antecedentes de consumo de alimentos crudos o parcialmente cocidos en las semanas recientes y tampoco había contacto con mascotas. La evolución fue favorable. Aunque no se estudió la susceptibilidad del aislado, se presumió resistencia a quinolonas ya que el cuadro apareció durante el uso profiláctico de ciprofloxacina para infección urinaria. En contraste con $C$. jejuni, las infecciones por $C$. fetus se asocian a pacientes debilitados o inmunosuprimidos, se manifiestan predominantemente como bacteriemias sin diarrea y no tiene un perfil autolimitado.

\section{Referencias}

1.- Koneman E W, Allen S D, Janda W M, Schreckenberg P C, Winn W C. Curved Gram-negative Bacilli and Oxidase Positive Fermenters: Campylobacters and Vibrionaceae. En: Koneman E W, Allen S D, Janda W M, Schreckenberg P C, Winn W C (Eds). Color Atlas and Textbook of Diagnostic Microbiology. 4th Edition. 1992. JB Lippincot Company, Philadelphia. pp 243-77.

2.- Allos N M. Campylobacter jejuni infections: Update on emerging issues and trends. Clin Infect Dis 2001; 15; 32: 1201-6.

3.- Kodaka H, Armfield A Y, Lombard G L, Dowell V R Jr. Practical procedure for demonstrating bacterial flagella. J Clin Microbiol 1982; 16: 948-52.

4.- Chanqueo L, García P, León E, Blu A. Evaluación de la tinción de Hucker para la búsqueda rutinaria de Campylobacter sp. en el estudio de un síndrome diarreico agudo. Rev Chil Infect 2005; 22: 242-6.

5.- Font C, Cruceta A, Moreno A, Miró O, Coll-
Vinent B, Almela M, et al. Estudio de 30 pacientes con bacteriemia por Campylobacter spp. Med Clin (Barc) 1997; 108: 336-40.

6.- Tremblay C, Gaudreau C, Lorange M. Epidemiology and antimicrobial susceptibilities of 111 Campylobacter fetus subsp. fetus strains isolated in Québec, Canada, from 1983 to 2000. J Clin Microbiol 2003; 41: 463-6.

7.- Chuman Y, Takata T, Sameshima H, Takeuchi S, Takatsuka Y, Makino T, et al. Campylobacter fetus bacteremia in a patient with adult $\mathrm{T}$ cell leukemia. Clin Infect Dis 2003; 36: 1497-8.

8.- Heng A E, De Champs C, Souweine B, Guy L, Sirot J, Deteix P. Campylobacter fetus bacteraemia in a renal graft recipient. Nephrol Dial Transplant 2002; 17: 689-90.

9.- Tu ZC, Zeitlin G, Gagner J P, Keo T, Hanna B A, Blaser M J. Campylobacter fetus of reptile origin as a human pathogen. $\mathrm{J}$ Clin Microbiol 2004; 42: 4405-07.

10.- Stuck A E, Minder C E, Frey F J. Risk of infectious complications in patients taking glucocorticosteroids. Rev Infect Dis 1989; 11: 954-63.

11.- Remacha M A, Esteban A, GonzálezCastañeda C, Fernández-Natal I, Echeita A. Bacteriemia por Campylobacter fetus en paciente inmunocompetente. An Med Interna (Madrid) 2003; 20: 55-6.

12.- Centers for Disease Control (CDC). Campylobacter sepsis associated with "nutritional therapy"--California. MMWR Morb Mortal Wkly Rep 1981; 30: 294-5.

13.- Devlin H R, McIntyre L. Campylobacter fetus subsp. fetus in homosexual males. J Clin Microbiol 1983;18: 999-1000.

14.- Prado V, Martínez J, Reyes L, Ducheylard M, Bercovich M, Millán V, et al. Características de la infección intestinal por Campylobacter jejuni en lactantes chilenos. Rev Méd Chile 1985; 113: 521-5.

15.- Herve J, Aissa N, Legrand P, Sorkine M. Calmette M J, Santin A, et al. Campylobacter fetus meningitis in a diabetic adult cured by imipenem. Eur J Clin Microbiol Infect Dis 2004; 23: 722-4. 